\title{
GAMBARAN TINGKAT SELF-EFFICACY DALAM KEPUTUSAN KARIR PESERTA DIDIK DI SEKOLAH PENYELENGGARA PROGRAM PEMINATAN \\ (Survei Terhadap Peserta Didik Kelas VIII SMP Negeri 99 Jakarta Tahun Ajaran 2015/2016)
}

\author{
Herdi $^{1}$ \\ Sjenny A Indrawati ${ }^{2}$ \\ Fajar Rona Ulfa ${ }^{3}$
}

\begin{abstract}
Abstrak
Tujuan penelitian ini untuk mendapatkan data empirik mengenai profil self-efficacy keputusan karir peserta didik di Sekolah Menengah Pertama Negeri (SMPN) 99 Jakarta. Teknik sampling yang digunakan ialah teknik systematic sampling dengan jumlah responden 168 peserta didik kelas VIII di Sekolah Menengah Pertama Negeri (SMPN) 99 Jakarta. Instrumen penelitian menggunakan instrumen model skala psikologi. Pengumpulan data menggunakan instrumen model skala psikologi yang berisi 46 item pernyataan yang bertingkat. Analisis uji validitas instrumen menggunakan Product Moment Pearson dengan bantuan software Statistical Package for the Social Sciences (SPSS) Versi 20.0. Uji reliabilitas dengan rumus Alpha Cronbach dengan bantuan software Statistical Package for the Social Sciences (SPSS) Versi 20.0. hingga diperoleh hasil 0,890 yang berarti bahwa instrumen memiliki reliabilitas tinggi dan layak digunakan sebagai instrumen penelitian. Hasil penelitan menunjukkan 81,55 \% self-efficacy keputusan karir peserta didik kelas VIII di sekolah menengah pertama Negeri (SMPN) 99 Jakarta berada pada kategori sedang, $14,85 \%$ berada pada kategori rendah, dan 3,6\% self-efficacy keputusan karir peserta didik kelas VIII di sekolah menengah pertama Negeri (SMPN) 99 Jakarta berada pada kategori tinggi. Ditandai dengan perkembangan kapasitas, sikap, minat, dan kebutuhan yang terkait dengan konsep diri. Konsep diri yang dimiliki individu terbentuk melalui identifikasi terhadap figur-figur keluarga dan lingkungan sekolah.
\end{abstract}

Kata Kunci: Self-Efficacy Keputusan Karir, Program Peminatan, Efikasi Diri, Keputusan Karir, Peserta Didik Kelas VIII

\section{SURVEY OF SELF-EFFICACY IN CAREER DECISION OF STUDENTS IN SCHOOL PROGRAM ORGANIZERS PEMINATAN}

\begin{abstract}
The purpose of this study to obtain empirical data on the profile of the career decision selfefficacy of students in Junior High School (SMPN) 99 Jakarta. The sampling technique used is the technique of systematic sampling with the number of respondents 168 learners in Grade VIII Junior High School (SMPN) 99 Jakarta.The research instrument using the instrument scale model of psychology. Collecting data using the instrument scale model of psychology that contains 46 items graded statements. Analysis test the validity of the instrument using Pearson Product Moment with the help of software Statistical Package

\footnotetext{
${ }^{1}$ Dosen Program Studi Bimbingan dan Konseling FIP UNJ, herdiunj5@gmail.com

2 Dosen Program Studi Bimbingan dan Konseling FIP UNJ, shartono@jisedu.or.id

${ }^{3}$ Mahasiswa Program Studi Bimbingan dan Konseling FIP UNJ, fajar.rona.ulfa.kuliah@gmail.com
} 
for the Social Sciences (SPSS) version 20.0. Test reliability with Cronbach alpha formula with the help of software Statistical Package for the Social Sciences (SPSS) version 20.0. to obtain the results of 0.890 which means that the instrument has high reliability and fit for use as a research instrument. The results showed $81.55 \%$ self-efficacy of career decision VIII grade students in junior high school (SMPN) 99 Jakarta middle category, $14.85 \%$ were in the low category, and $3.6 \%$ self-efficacy of career decision VIII grade students in junior high school (SMPN) 99 Jakarta is in the category at the high category. Characterized by the development of capacity, attitudes, interests, and needs related to self-concept. The self-concept of the individual is formed through the identification of the figures of the family and school environments.

Keyword: Career Decision Making Self-efficacy, Program Providers Of Peminatan, Selfefficacy, Career Decision Making, Eighth Grade Students

\section{PENDAHULUAN}

Karir yang melekat pada diri individu saat ini tidak dapat terlepas dari pengalaman yang telah terjadi, dan pengalaman yang sedang terjadi. Dengan kata lain, untuk mendapatkan karir tersebut ada sebuah proses pengalaman sepanjang rentang kehidupan individu.

Pengertian karir sendiri menurut Bruce Shertzer dalam Dewa Ketut Sukardi(1985) ialah karir sebagai suatu rangkaian pekerjaanpekerjaan, jabatan-jabatan, dan kedudukan, yang dipegang oleh orang/seseorang seumur hidupnya. Karir merupakan salah satu faktor penunjang dalam pengembangan kehidupan individu. Maka, disini keputusan karir sangat diperlukan karena merupakan kebutuhan pokok bawah sadar. Maka, dapat disimpulkan bahwa karir merupakan alat penunjang pengembangan kehidupan individu yang berupa suatu rangkaian pekerjaan, jabatan dan kedudukan.

Karir tidak pernah terlepas dari proses individu menjalakan pendidikan pada masa sebelum mendapatkan karir. Pendidikan merupakan upaya untuk membantu perkembangan sebagai makhluk individu dan sosial, sehingga anak dapat hidup secara layak dalam kehidupannya. Pendidikan membekali anak dengan berbagai ilmu pengetahuan, yang dikembangkan dengan nilai-nilai moral dan keterampilannya.

\section{ACUAN TEORITIK}

\section{SELF-EFFICACY}

Albert Bandura (1994) "Perceived self-efficacy is defined as people's beliefs about their capabilities to produce designated levels of performance that exercise influence over events that affect their lives. Selfefficacy beliefs determine how people feel, think, motivate themselves and behave. Such beliefs produce these diverse effects through four major processes. They include cognitive, motivational, affective and selection processes". Artinya self-efficacy sebagai keyakinan individu tentang kemampuan mereka untuk menghasilkan rancangan tingkat kinerja yang mempunyai pengaruh atas peristiwa yang mempengaruhi kehidupan mereka. Keyakinan self-efficacy menentukan perasaan individu, berpikir, memotivasi diri dan berperilaku. Keyakinan tersebut menghasilkan efek yang beragam melalui empat proses utama. Meliputi proses kognitif, motivasional, afektif dan seleksi. Dimensidimensi yang terdapat pada self-efficacy, yaitu: (1) Tingkat keyakinan (Magnitude atau Level) Dimensi ini berhubungan dengan tingkat kesulitan masalah atau tugas yang dapat diatasi oleh seseorang sebagai hasil presepsi tentang kompetensi dirinya. (2) Kekuatan Keyakinan (Strength)Dimensi ini berhubungan dengan kekuatan atau kelemahan keyakinan tentang kompetensi yang dipresepsinya. Dengan kata lain dimensi ini menunjukan tentang derajat 
kemantapan seseorang terhadap keyakiannya. (3) Luas Bidang Prilaku (Generality) Dimensi ini berhubungan dengan keluasan pencapaian keberhasilan seseorang dalam berbagai aktifitas atau hanya dominan pada fungsi tertentu.

Keputusan Karir

Tiedeman dan O'Hara (2000;21) mendefinisikan pembuatan keputusan, yaitu: Developed a decision-making model which attempted to combine personal awareness with appropriate external information. Keputusan merupakan model yang berusaha untuk menggabungkan kesadaran pribadi dengan informasi eksternal yang sesuai. Selanjutnya Tiedeman dan O'Hara mengemukakan 'Model is comprised of two phases: anticipation and accommodation. The anticipation phase refers to the stages prior to action, and includes four stages: exploration, crystallization, choice, and clarification. The accommodation phase reflects the stages individuals encounter after beginning to implement a decision and is comprised of three stages: induction, reformation, and integration". Model pengambilan keputusan yang terdiri dari dua tahap, yaitu antisipasi dan akomodasi. Tahap antisipasi mengacu pada tahap-tahap sebelum tindakan yang didalamnya meliputi tahapan eksplorasi, kristalisasi, pilihan, dan kalrifikasi. Sedangkan tahap akomodasi ialah tahap yang mencerminkan diri individu setelah melaksanakan keputusannya. Sejalan dengan pendapat Tiedeman dan O'Hara, Krumboltz "Emphasizes the environmental and social influences upon career choice and development". Krumboltz menekankan lingkungan dan sosial berpengaruh pada pemilihan karir dan pengembangan.Super mendefinisikan pengambilan keputusan karir sebagai salah satu bagian terpenting dalam konsep kematangan karir. Dimensi ini mengukur pengetahuan tentang prinsip dan cara pengambilan keputusan. Individu memiliki kemandirian, membuat pilihan pekerjaan yang sesuai dengan minat dan kemampuan kemampuan untuk menggunakan metode dan prinsip pengambilan keputusan untuk menyelesaikan masalah termasuk memilih pendidikan dan pekerjaan. Berdasarkan pendapat Tiedeman dan O'Hara, Krumboltz maupun Super dapat disimpulkan bahwa keputusan karir adalah proses pengambungan yang melibatkan faktor dari diri sendiri (internal) dan faktor luar diri (eksternal) yang melekat pada kehidupan sehari-sehari yang dijalakan individu. Agar mencapai keputusan karir yang tepat seorang peserta didik harus mengenal dan mempertimbangkan faktor internal dan eksternal diri mereka sendiri.

\section{METODE PENELITIAN}

Metode penelitian yang digunakan dalam penelitian ini menggunakan survey. Metode deskriptif digunakan untuk mendapatkan gambaran atau uraian atas suatu keadaan sejelas mungkin tanpa ada perlakuan terhadap objek yang diteliti. Penelitian ini bertujuan untuk mendapatkan gambaran tingkat self-efficacy dalam keputusan karir siswa kelas VIII di SMPN 99 Jakarta .

\section{HASIL PENELITIAN}

Hasil penelitian menggunakan instrumen self - efficacy keputusan karir yang berjumlah 46 butir pernyataan menunjukan hasil bahwa peserta didik SMPN 99 Jakarta 81,55\% self - efficacy keputusan karir peserta didik tergolong sedang, $14,85 \%$ self - efficacy keputusan karir peserta didik tergolong rendah, dan 3,6\% memiliki self - efficacy keputusan karir tergolong tinggi.

\begin{tabular}{cccc}
\hline $\begin{array}{c}\text { Rentang } \\
\text { Skor }\end{array}$ & Kategori & Frekuensi & $\%$ \\
\hline $\mathrm{X}>150$ & Tinggi & 6 & 3,6 \\
$12 \leq \mathrm{X} \leq 150$ & Sedang & 137 & 81,55 \\
$\mathrm{X} \leq 150$ & Rendah & 25 & 14,85 \\
Jumlah & & & 100 \\
\hline
\end{tabular}

Tabel 1. Self - Efficacy Keputusan Karir Peserta Didik Kelas VIII di SMP Negeri 99 Jakarta 


\section{Gambaran Self - Efficacy dalam Keputusan Karir Peserta Didik Kelas VIII di SMP Negeri 99 Jakarta}

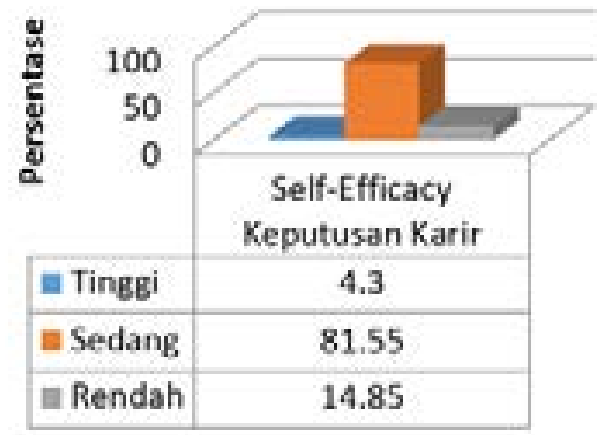

Diagram 1. Self-Efficacy Keputusan Karir Peserta Didik Kelas VIII di SMP Negeri 99 Jakarta

Sehingga dapat disimpulkan bahwa self - efficacy keputusan karir pada peserta didik kelas VIII di SMP Negeri 99 Jakarta tergolong sedang.

Hasil penelitian dari 3 dimensi self - efficacy keputusan karir peserta didik kelas VIII keseluruhannya memiliki self - efficacy keputusan karir yang dapat dilihat dari diagram 4.2:

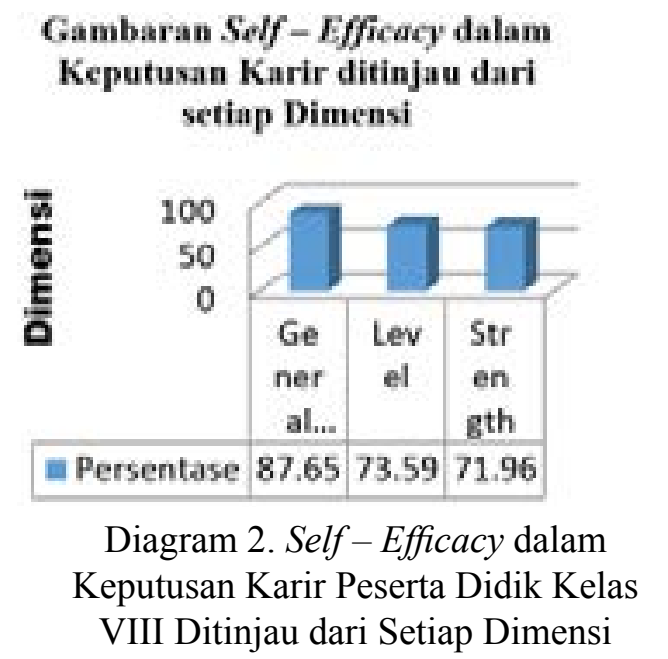

Berdasarkan diagram 2 dapat dilihat bahwa dimensi yang paling tinggi persentasenya adalah dimensi generality $(87.65 \%)$, diikuti dengan dimensi level (73.59\%), urutan terakhir dimensi strength (71.96\%).

\section{KESIMPULAN, IMPLIKASI DAN SARAN}

Berdasarkan hasil penelitian yang telah dilakukan mengenai profil self-efficacy keputusan karir difokuskan pada peserta didik kelas VIII SMP Negeri 99 Jakarta dapat disimpulkan bahwa sebagian besar peserta didik kelas VIII SMP Negeri 99 Jakarta memiliki self-efficacy keputusan karir dalam kategori sedang. $81,55 \%$ sedang. $14,85 \%$ rendah dan $3,6 \%$ tingggi.

Hasil penelitian ini dapat menggambarkan keadaan dan fakta di lapangan mengenai self-efficacy dalam keputusan karir yang ada di SMP Negeri 99 Jakarta sebagai sekolah penyelenggara program peminatan. Peserta didik perlu memiliki self-efficacy dalam keputusan karir agar mampu memutuskan karirnya dimasa depan, mengembangkan informasi karir sehingga dapat menentukan keptusan karir masa depan yang sesuai.

Sebagian besar peserta didik SMP Negeri 99 Jakarta memiliki self-efficacy dalam keputusan karir tergolong sedang, sehingga dapat disimpulkan bahwa peserta didik kelas VIII di SMP Negeri 99 Jakarta cukup mampu memutuskan sendiri karirnya dimasa depan, dan akan mendapatkan kepuasan dan kesesuaian karir dimasa depan. Apabila peserta didik pada kelas tinggi memiliki self-efficacy keputusan karir rendah maka hal ini akan berpengaruh pada pemilihan karir atau pemilihan jurusan yang ada di SMA/SMK dan akan berpengaruh pada tahap selanjutnya yaitu pada karir masa depan yang peserta didik pilih. Semakin peserta didik memiliki self-efficacy dalam keputusan karir yang tinggi maka diharapkan tidak lagi ditemukan masalah ketidak sesuaian dalam keputusan karir.

Saran - saran yang dapat menjadi pertimbangan berdasarkan hasil penelitian ini 
adalah sebagai berikut:

1. Bagi peserta didik, disarankan untuk lebih dapat memanfaatkan program peminatan yang ada pada sekolah dan memanfaatkan layanan BK yang ada di sekolah secara optimal.

2. Bagi pihak sekolah

a. Guru BK, disarankan untuk lebih membantu peserta didik dalam keputusan karir agar mendapatkan gambaran jelas mengenai karir masa depan dan agar peserta didik bisa mengambil keputusan karir masa depan.

b. Guru Mata Pelajaran, disarankan untuk lebih membantu secara teori dan praktik dalam pembelajaran peserta didik sehingga pengetahuan dan keterampilan peserta didik dapat dikembangkan.

3. Bagi peneliti selanjutnya

a. Menambahkan sampel penelitian lebih besar lagi, seperti sampel pada satu wilayah kota administrasi;

b. Membuat penelitian mengenai perbandingan antara sekolah penyelenggara program peminatan dan sekolah non-penyelenggara program peminatan;

c. Menambahkan variabel lain terkait self-efficacy keputusan karir, seperti pengaruh dukungan sosial terhadap self-efficacy keputusan karir;

d. Mengembangkan program BK karir sebagai pendukung self-efficacy keputusan karir.

\section{DAFTAR PUSTAKA}

Azwar, S. (2012). Penyusunan Skala Psikologi.
Yogyakarta: Pustaka Pelajar.

Bernes. (2000). A Synergistic Model of Organization Career Development. Canada: Life-Role Development Group Limited.

Super, C.M., \& Super, D.E. (2001). Opportunities in Psychology Careers. USA: McGraw Hill.

Savickas, M.L. (2011). Career Counseling: Theory of Psychoteraphy Series. Washington, DC: American Psychological Association. 


\section{Lampiran}

\section{Instrumen Self-Efficacy Keputusan Karir}

\section{Nama:}

\section{Kelas:}

Kuesioner ini diberikan dalam rangka penelitian skripsi yang bertujuan untuk memperoleh data tentang gambaran self-efficacy dalam keputusan karir di sekolah penyelenggara program pemintan, maka saya meminta kesediaan adik - adik untuk mengisi kuesioner ini.

Atas perhatian dan kerjasamnya saya ucapkan terima kasih.

Petunjuk pengisian:

1. Bacalah pernyataan dibawah ini dengan teliti;

2. Gunakan pensil atau pena untuk mengisi kuesioner ini;

3. Berilah tanda Checklist $(\sqrt{ })$ pada salah satu jawaban yang dianggap paling tepat dan sesuai dengan keadaan kamu;

4. Jawaban yang kamu berikan tidak akan mempengaruhi nilai apapun, maka dari itu isilah dengan jujur.

5. Alternatif jawabannya adalah sebagai berikut:

SL: Selalu

SR: Sering

KK: Kadang - Kadang

TP: Tidak Pernah

Contoh:

Pada lembar soal terdapat pernyataan sebagai berikut. Kemudian kamu harus memilih salah satu dari empat jawaban dengan memberi tanda Checklist $(\sqrt{ })$.

\begin{tabular}{llcccc}
\hline NO & \multicolumn{1}{c}{ PERNYATAAN } & SL & SR & KK & TP \\
\hline 1. & $\begin{array}{l}\text { Saya menanyakan informasi karir yang ingin saya } \\
\text { ketahui kepada teman. }\end{array}$ & $\sqrt{ }$ & & & \\
\hline
\end{tabular}




\begin{tabular}{l|lllll}
\hline NO & PERNYATAAN & SL & SR & KK & TP \\
\hline 1 & Sayamampumenguai & &
\end{tabular}

1. Saya mampu menguasai tugas-tugas di sekolah untuk menunjang karir masa depan.

2. Saya dapat bersaing dengan teman-teman di kelas dalam mendapatkan peringkat kelas.

3. Kesuksesan dalam berkarir ditentukan oleh ketekunan saya dalam belajar.

4. Saya ragu saat akan memutuskan hal yang berkaitan dengan karir saya di masa depan.

5. Saya mampu bersaing untuk menghadapi tantangan karir masa depan.

6. Saya dapat memenuhi persyaratan untuk mendapatkan sekolah SMA/SMK yang diinginkan.

7. Saya tidak yakin terhadap pilihan karir saya di masa depan.

8. Saya dapat melanjutkan sekolah SMA/SMK dengan minat yang dimiliki.

9. Saya mampu mengembangkan minat sesuai dengan cita-cita.

10. Saya dapat mengetahui berbagai minat yang ada pada diri sendiri untuk mengejar masa depan.

11. Saya akan menekuni karir yang sesuai dengan minat yang saya miliki.

12. Bakat yang dimiliki sesuai dengan minat karir yang saya inginkan.

13. Saya dapat memilih keputusan karir sesuai minat yang dimiliki.

14. Saya dapat meningkatkan keterampilan berkomunikasi dengan mengikuti kursus Bahasa Inggris.

15. Saya dapat meraih cita-cita dengan kamampuan Bahasa Inggris yang dimiliki.

16. Saya mampu mencapai tujuan yang dicita-citakan dengan kemampuan keterampilan komunikasi. 


\begin{tabular}{llllll}
\hline NO & PERNYATAAN & SL & SR & KK & TP \\
\hline 17. & Saya mengikuti kursus & TPmputer untuk meningkatkan & &
\end{tabular}

17. Saya mengikuti kursus komputer untuk meningkatkan keterampilan dalam menunjang karir di masa depan.

18. Saya senang aktif di kegiatan ekstrakurikuler untuk mengasah keterampilan karir masa depan.

19. Saya dapat menentukan sendiri keputusan karir di masa depan.

20. Saya menggunakan pengetahuan karir dalam mengambil keputusan karir masa depan.

21. Saya dapat mengetahui cara-cara dalam membuat keputusan karir.

22. Saya dapat mempelajari cara orang lain (orang tua, saudara dan/atau teman dekat) dalam membuat keputusan.

23. Saya mampu merencanakan karir untuk lima tahun kedepan.

24. Saya mampu membuat rencana keberhasilan dalam setiap tugas.

25. Saya dapat mencoba hal-hal baru tanpa mengeluh.

26. Saya tidak malu bertanya kepada teman mengenai informasi karir masa depan.

27. Saya termotivasi dalam pencapaian karir jika berdiskusi dengan orang-orang berpengalaman.

28. Saya mencari informasi dari berbagai media mengenai sekolah SMA/SMK yang sesuai karir masa depan.

29. Saya mampu membuat keputusan karir sesuai potensi yang dimiliki.

30. Saya dapat merencakan karir berdasarkan informasi yang diberikan guru BK.

31. Saya dapat mendiskusikan keputusan karir bersama orang tua.

32. Saya dapat mengetahui potensi diri dengan berkonsultasi bersama guru BK.

33. Saya aktif pada kegiatan ektrakurikuler di sekolah

34. Saya mengikuti ektrakurikuler di sekolah hanya sebagai syarat mata pelajaran tertentu. 


\begin{tabular}{llllll}
\hline NO & PERNYATAAN & SL & SR & KK & TP \\
\hline
\end{tabular}

35. Saya memikirkan tentang rencana apa yang akan dilakukan setelah lulus SMP.

36. Saya tidak begitu memikirkan tentang rencana apa yang akan dilakukan setelah lulus SMP.

37. Saya akan memilih sekolah SMA/SMK tanpa paksaan dan pengaruh dari orang lain.

38. Saya memiliki sejumlah pekerjaan yang dipertimbangkan, jika pekerjaan yang diinginkan tidak bisa didapat.

39. Saya mampu memperbaiki kegagalan dengan cara belajar.

40. Saya mampu mengatasi kesulitan dengan belajar kelompok.

41. Saya termotivasi untuk belajar lebih giat ketika mendapatkan nilai mata pelajaran yang kurang

42. Saya dapat mengambil hikmah dari kegagalan yang saya alami.

43. Saya menjadikan kegagalan sebagai motivasi mencapai kesuksesan.

44. Kebehasilan orang lain menjadikan motivasi saya dalam mencapai karir masa depan.

45. Pengalaman bekerja sama dengan orang lain lebih memudahkan saya mengambil keputusan.

46. Saya akan menyerah ketika mendapatkan masalah. 